\title{
Left ventricular infarct plication restores mitral function in chronic ischemic mitral regurgitation
}

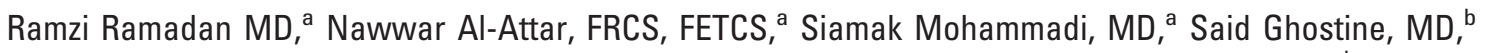 \\ Alexandre Azmoun, MD, alexis Therasse, MD, ${ }^{a}$ Chokri Kortas, MD, ${ }^{a}$ Christophe Caussin, MD, \\ and Rémi Nottin, MD, ${ }^{a}$ Le Plessis-Robinson, France
}

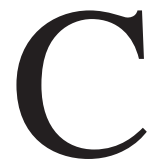
hronic ischemic mitral regurgitation (IMR) is characterized by restricted leaflet closure with increased leaflet tethering caused by displaced attachment of the papillary muscle (PM). ${ }^{1}$ Generally, the posterior PM is displaced by ventricular remodeling after posterolateral myocardial infarction. ${ }^{2}$ IMR carries a significantly negative prognostic effect for cardiac mortality within 5 years, even in patients without signs of established heart failure. ${ }^{3}$

A variety of surgical techniques of repairing or replacing the mitral valve have been advocated. These techniques are generally technically demanding and necessitate opening the left side of the heart. Experimental work on ventricular remodeling through reduction of the left ventricular circumference by plication of the left ventricle (LV) can restore mitral geometry toward a normal level. ${ }^{4}$ Recently, an external device that repositions the PM has been shown to reduce IMR without compromising LV function. ${ }^{5}$

We report the first 3 cases in human subjects of chronic IMR treated by means of plication of the fibrotic infarct in the posterolateral wall of the LV simultaneously with a coronary revascularization procedure without mitral annuloplasty.

\section{Methods}

Between January 2003 and June 2003, 3 male patients underwent plication of the left ventricular infarct scar as an adjunct to myocardial revascularization. Mean age was 58.3 years (range, 51-67 years). All patients had moderately severe (grade 3-4) mitral regurgitation (MR). The median time lag between the occurrence of MI and surgical intervention was 50 months (range, 6-60 months).

In all patients IMR was caused by localized left ventricular posterolateral postinfarction fibrotic scarring with echocardiographic evidence of restrictive motion of the mitral valve (type $3 \mathrm{~b}$ of Carpentier's classification). Ventricular measures are shown in Table 1.

\footnotetext{
From the Department of Adult Cardiovascular Surgery ${ }^{\mathrm{a}}$ and the Department of Cardiology, ${ }^{\mathrm{b}}$ Marie-Lannelongue Hospital, Le Plessis-Robinson, France.

Received for publication April 14, 2004; revisions received May 5, 2004 accepted for publication May 10, 2004.

Address for reprints: Ramzi Ramadan, MD, Marie-Lannelongue Hospital, 133 Ave de la Résistance, 92350 Le Plessis-Robinson, France (E-mail: ramadan.ramzi@wanadoo.fr).

J Thorac Cardiovasc Surg 2005;129:440-2

$0022-5223 / \$ 30.00$

Copyright $\odot 2005$ by The American Association for Thoracic Surgery

doi:10.1016/j.jtcvs.2004.05.017
}

Left ventricular plication is performed before coronary artery bypass grafting (CABG). Identifying the borders of the dyskinetic or akinetic fibrotic area is aided by vigorous aortic venting, which creates a depression corresponding to the infarct zone. The center of the infarct is pulled out by a stitch to facilitate plication of this segment with a series of $U$ sutures. Our choice of suture material is polypropylene $2-0$ on a $36-\mathrm{mm}$ needle reinforced with a Teflon patch. The suture bites are made deep, transfixing into both edges of the fibrotic zone and parallel to the longitudinal axis of the LV (Figure 1). No mitral annuloplasty was associated with this procedure.

CABG is performed exclusively by thoracic artery grafting. No myocardial revascularization procedure was performed in the territory of the plication.

Perioperative transesophageal echocardiography demonstrated the disappearance of MR in all patients. Two patients had no MR, and one had only trivial MR on follow-up echocardiography after a mean of 7 months (range, 3-9 months). The New York Heart Association functional class decreased from III to II in all patients.

\section{Discussion}

The exact mechanisms of the development of IMR are not completely clarified, with various factors contributing to the reduced leaflet coaptation. Consequently, the surgical management of IMR remains controversial.

Mitral annuloplasty to reduce annular size forms a standard procedure in the reduction of MR. However, the main pathologic process involved in IMR is ventricular deformation that cannot be treated with a pure annular solution; therefore, we propose an innovative approach to treat moderate and severe IMR.

Recent work has shown that relief of IMR as a unique objective has a limited effect on remodeling, which seems to explain the negligible effect of mitral valve replacement or annuloplasty on survival. An infarct-induced myopathy is produced by expansion (stretching) of a transmural myocardial infarction initially localized to the myocardium adjacent to the infarct but that extends during the remodeling process to include contiguous uninvolved myocardium. ${ }^{6}$ Our approach consists of plication of the fibrotic segment after an inferior myocardial infarction, aiming to restore left ventricular geometry and eliminating the otherwise deleterious effect of the dyskinetic area. This procedure precludes opening of the left side of the heart, as opposed to all previously described techniques. Relieving ischemia remains an important adjunct procedure, and all patients had CABG, although not in the zone of the plication.

Our initial results of 3 patients are shown in Table 1. A notable finding was the significant reduction in ventricular volumes after 

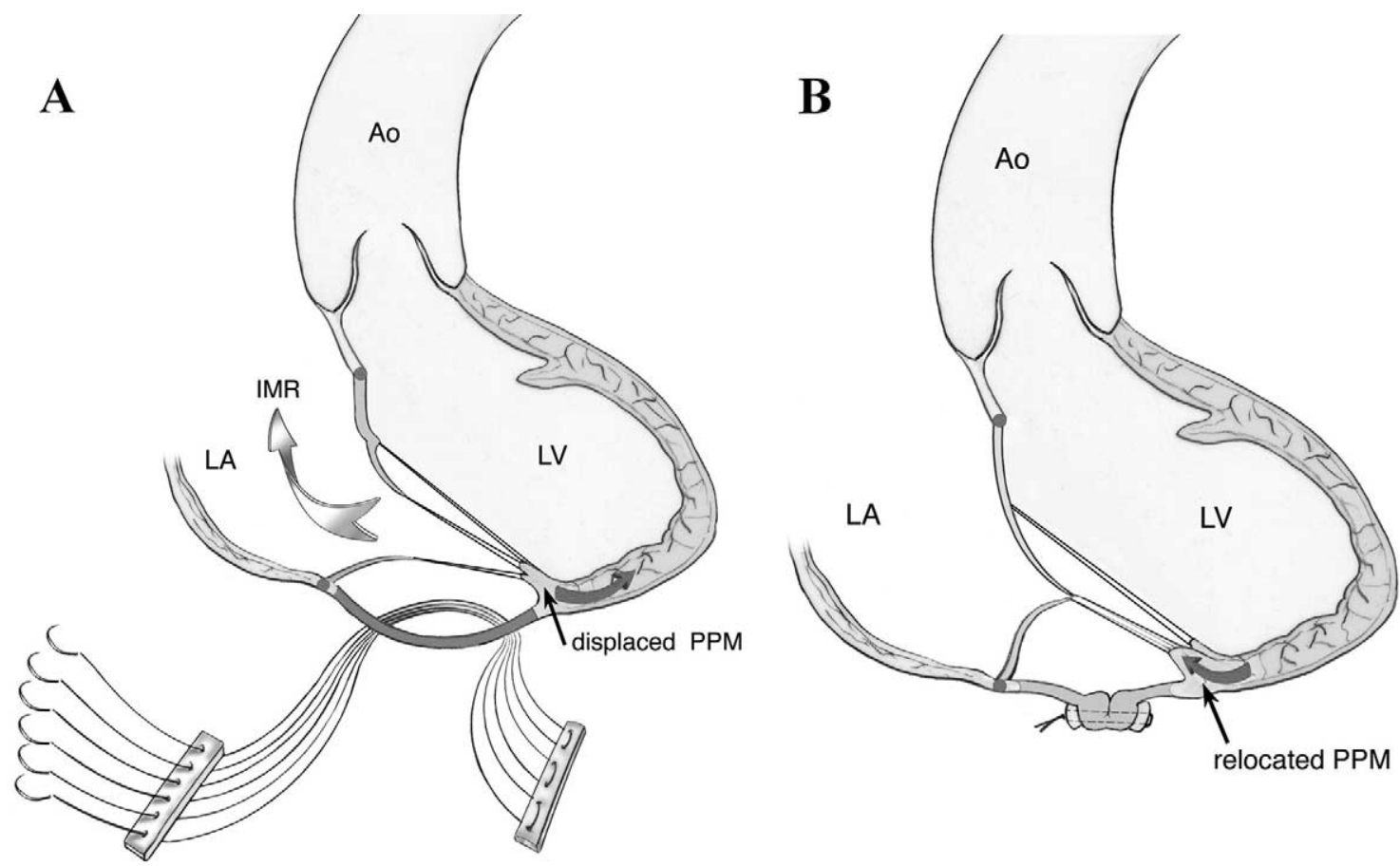

Figure 1. A, Schematic representation of the akinetic inferobasal segment with tethering of the posterior leaflet. The sutures are shown before tightening. B, Plication of the dyskinetic segment with relocation of the posterior papillary muscle. $L A$, Left atrium; $L V$, left ventricle; $A o$, aorta; IMR, ischemic mitral regurgitation; PPM, posterior papillary muscle.

\section{TABLE 1. Patient data}

\begin{tabular}{|c|c|c|c|c|c|c|c|c|c|}
\hline & Age (y) & Sex & $\begin{array}{c}\text { Time lag from } \\
\text { MI (mo) }\end{array}$ & CABG & $\begin{array}{l}\text { LVEDV } \\
(\mathrm{mL})\end{array}$ & $\begin{array}{l}\text { LVESV } \\
(\mathrm{mL})\end{array}$ & $\begin{array}{l}\text { LVEF } \\
(\%)\end{array}$ & $\begin{array}{l}\text { LVEDd } \\
(\mathrm{mm})\end{array}$ & $\begin{array}{c}\text { LVESd } \\
(\mathrm{mm})\end{array}$ \\
\hline Patient 1 & 67 & M & 6 & 3 & 217 & 96 & 56 & 56 & 38 \\
\hline Patient 1 , postoperatively & & & & & 177 & 76 & 57 & 54 & 36 \\
\hline Patient 2 & 51 & M & 60 & 4 & 261 & 212 & 19 & 68 & 55 \\
\hline Patient 2, postoperatively & & & & & 183 & 106 & 37 & 62 & 47 \\
\hline Patient 3 & 57 & M & 50 & 3 & 171 & 92 & 46 & 55 & 44 \\
\hline Patient 3, postoperatively & & & & & 143 & 74 & 48 & 54 & 39 \\
\hline
\end{tabular}

$M I$, Myocardial infarction; $C A B G$, coronary artery bypass grafting; $L V E D V$, left ventricular end-diastolic volume; $L V E S V$, left ventricular end-systolic volume; $L V E F$, left ventricular ejection fraction; $L V E D$ d, left ventricular end-diastolic dimension; $L V E S d$, left ventricular end-systolic dimension.

plication. Concomitantly, the left ventricular ejection fraction improved in all patients, despite the resolution of the MR. There was no compromise of systolic function and no increase in filling pressures.

Plication of the left ventricular infarction is a relatively simple procedure in the surgical management of IMR. It can be combined with myocardial revascularization and avoids opening the left side of the heart. Our initial experience shows encouraging early-term outcomes, despite the poor prognosis of such patients. However, long-term follow-up on a greater number of patients is necessary to determine the true effect of this technique.

\section{References}

1. Godley RW, Wann LS, Rogers EW, Feigenbaum H, Weyman AE. Incomplete mitral leaflet closure in patients with papillary muscle dysfunction. Circulation. 1981;63:565-71

2. Kumanohoso T, Otsuji Y, Yoshifuku S, Matsukida K, Koriyama C, Kisanuki A, et al. Mechanism of higher incidence of ischemic mitral regurgitation in patients with inferior myocardial infarction: quantitative analysis of left ventricular and mitral valve geometry in 103 patients with prior myocardial infarction. $J$ Thorac Cardiovasc Surg. 2003;125:135-43.

3. Lamas GA, Mitchell GF, Flaker GC, Smith SC Jr, Gersh BJ, Basta L, et al. Clinical significance of mitral regurgitation after acute myocardial 
infarction. Survival and Ventricular Enlargement Investigators. Circulation. 1997;96:827-33.

4. Liel-Cohen N, Guerrero JL, Otsuji Y, Handschumacher MD, Rudski LG, Hunziker PR, et al. Design of a new surgical approach for ventricular remodeling to relieve ischemic mitral regurgitation: insights from 3-dimensional echocardiography. Circulation. 2000;101:2756-63.

5. Hung J, Guerrero JL, Handschumacher MD, Supple G, Sullivan S,
Levine RA. Reverse ventricular remodeling reduces ischemic mitral regurgitation: echo-guided device application in the beating heart. Circulation. 2002;106:2594-600.

6. Guy TS 4th, Moainie SL, Gorman JH 3rd, Jackson BM, Plappert T, Enomoto Y, et al. Prevention of ischemic mitral regurgitation does not influence the outcome of remodeling after posterolateral myocardial infarction. J Am Coll Cardiol. 2004;43:377-83.

\section{Robotically assisted repair of sinus venosus defect}

Emile A. Bacha, MD, ${ }^{a}$ Gil Bolotin, MD, ${ }^{a}$ Karen Consilio, PA-C, ${ }^{\text {a } J a i ~ R a m a n, ~ M D, ~ a n d ~ D a v i d ~ G . ~ R u s c h h a u p t, ~ M D, ~}{ }^{\text {b }}$ Chicago, III

omputer-enhanced telemanipulation systems, also called robotic surgery, have recently emerged as a less-invasive option for a variety of cardiac surgical procedures. ${ }^{1}$ The advantages of the computerized robotic enhancement systems include ergonometric movements, 3-dimensional optics with tremor filtration and high-resolution video magnification, and wristlike articulations at the end of each instrument, providing intracardiac 7 degrees of freedom available at the tip of the instrument. This report describes the first documented use of a robotic surgical system for repair of a sinus venosus defect.

\section{Clinical Summary}

A 40-year-old man with a long smoking history presented with increasing fatigue. A sinus venosus defect was diagnosed. Cardiac catheterization showed a Qp/Qs of 2.4 with normal pulmonary artery pressures. The technique developed by Kypson, Nifong, and Chitwood $^{1}$ was used. In the operating room, a double-lumen endotracheal tube was inserted, and the patient was positioned supine, with his right chest elevated at $30^{\circ}$ and the right arm tucked on the side. After heparinization, the right femoral artery and vein were cannulated, and the inferior vena cava cannula was positioned below the diaphragm with transesophageal echocardiographic (TEE) guidance. A superior vena cava $17 \mathrm{~F}$ arterial cannula (Medtronic Bio-Medicus, Eden Prairie, Minn) was placed percutaneously through the right internal jugular vein under TEE guidance. A 3-cm right anterolateral minithoracotomy was performed, entering the fourth intercostal space. A rigid rib retractor was not used. During

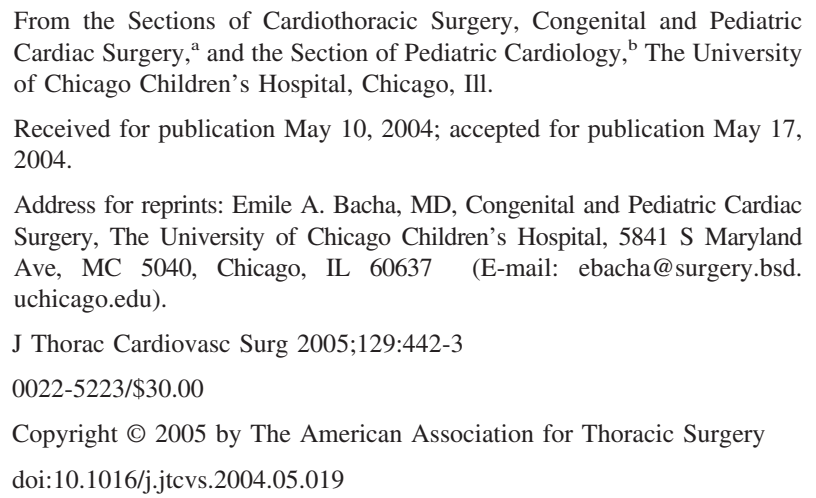

single-lung ventilation, the pericardium was opened, and a patch was harvested. The right-sided pulmonary venous drainage was inspected by using the $0^{\circ}$ endoscopic camera, and partial anomalous venous

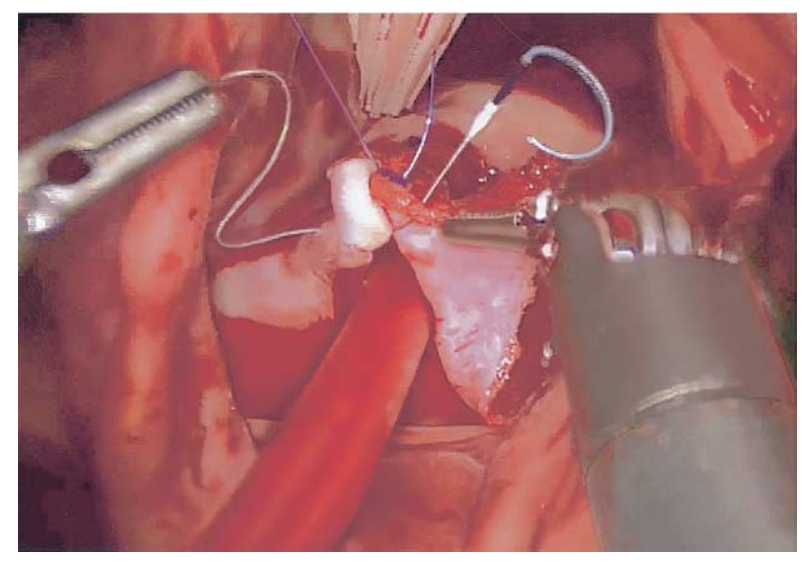

Figure 1. The first nitinol U-clip is being applied. The coil and its release mechanism (black and white portions of the clip) are clearly seen. A cardiotomy sucker is present in the left atrium and was introduced through the posterior aspect of the minithoracotomy.

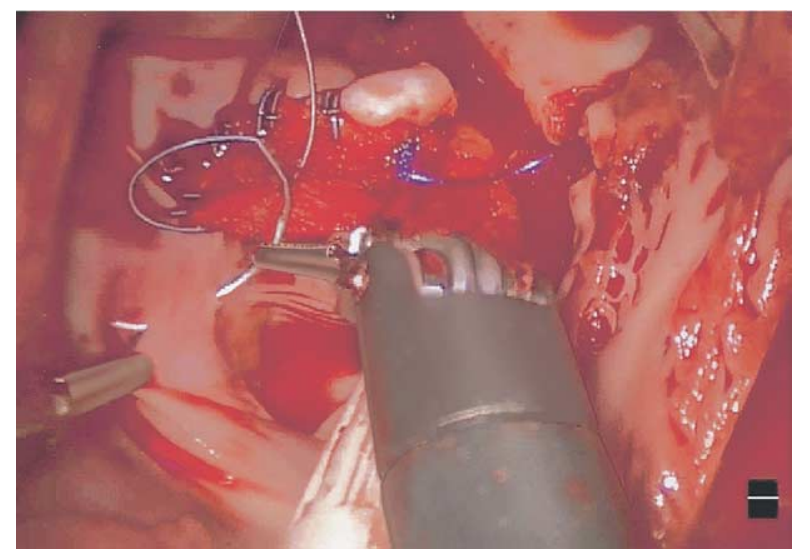

Figure 2. Several U-clips have been placed and released. The deployed coils are clearly visible. The limbus (superior aspect of the sinus venosus defect) is being grasped by the left robotic arm. 